Case Reports in
Gastroenterology
Case Rep Gastroenterol 2021;15:269-275

DOI: 10.1159/000512421

Published online: March 4, 2021
(C) 2021 The Author(s)

Published by S. Karger AG, Base www.karger.com/crg

This article is licensed under the Creative Commons Attribution-NonCommercial 4.0 International License (CC BY-NC) (http://www.karger.com/Services/OpenAccessLicense). Usage and distribution for commercial purposes requires written permission.

\title{
Primary Duodenal Carcinoma with Embryonal Carcinoma Features in a Young Man
}

\author{
Naoto Yamamoto ${ }^{a}$ Kota Washimi ${ }^{b}$ Masaaki Murakawa ${ }^{a}$ \\ Mariko Kamiya $^{a}$ Yuto Kamioka ${ }^{a}$ Makoto Ueno ${ }^{c}$ Takeshi Kishida ${ }^{d}$ \\ Yasushi Rino $^{\mathrm{e}}$ Munetaka Masuda $^{\mathrm{e}}$ Soichiro Morinaga ${ }^{\mathrm{a}}$ \\ aDepartment of Gastrointestinal Surgery, Kanagawa Cancer Center, Yokohama, Japan; \\ ${ }^{b}$ Department of Pathology, Kanagawa Cancer Center, Yokohama, Japan; 'Department of \\ Hepatobiliary and Pancreatic Medical Oncology, Kanagawa Cancer Center, \\ Yokohama, Japan; dDepartment of Urology, Kanagawa Cancer Center, Yokohama, Japan; \\ eDepartment of Surgery, Yokohama City University Hospital, Yokohama, Japan
}

\section{Keywords}

Duodenal cancer · Embryonal carcinoma - Germ cell tumor - Burned-out tumor ·

Pancreaticoduodenectomy

\begin{abstract}
We present the case of a 35-year-old man with intractable nausea, vomiting, and severe anemia. A computed tomography (CT) scan of the chest, abdomen, and pelvis showed a circumferential lesion thickening of up to $3.5 \mathrm{~cm}$ at the level of the third portion of the duodenum. No aortocaval, retroperitoneal lymphadenopathy, nor secondary lesion was observed. Esophagogastroduodenoscopy (EGD) revealed a circumferential mass within the third portion of the duodenum. Histopathology of biopsy materials from the duodenal mass showed it most likely to be a poorly differentiated adenocarcinoma. The patient underwent a subtotal stomach-preserving pancreaticoduodenectomy with regional lymph node dissection. Histologically, tumor cells with basophilic cytoplasm and pleomorphic nuclei showed a solid pattern, and expressed CD30 and SALL4 immunohistochemically, leading to a diagnosis of embryonal carcinoma-like tumor. No other primary tumor could be identified, and the location of the tumor, mainly on
\end{abstract}




\section{Case Reports in Gastroenterology}

Case Rep Gastroenterol 2021;15:269-275

\begin{tabular}{l|l}
\hline DOI: 10.1159/000512421 & $\odot 2021$ The Author(s). Published by S. Karger AG, Basel
\end{tabular} www.karger.com/crg

Yamamoto et al.: Primary Duodenal Carcinoma with Embryonal Carcinoma Features in a Young Man

the mucosal surface, suggested a duodenal origin. The UICC TNM staging was T3N2M0, stage IIB. This is a rare case of primary duodenal carcinoma with features of embryonal carcinoma.

(C) 2021 The Author(s)

Published by S. Karger AG, Basel

\section{Introduction}

Primary duodenal cancer (PDC), which arises from the region of duodenum, excluding ampullary regions of the Vater, is rare and accounts for less than $1 \%$ of all carcinomas of the gastrointestinal tract $[1,2]$. Histologically, adenocarcinoma and gastrointestinal stromal tumor (GIST) were the most common types of PDC. Other histological types included neuroendocrine carcinoma and adeno-squamous carcinoma [3]. Surgical approaches to cancer of the duodenum can vary and are highly dependent on the location of the tumor. Tumors that occur in the first, second, or third part of the duodenum usually require pancreaticoduodenectomy, but tumors that occur in the fourth part may be better suited for partial duodenal resection.

Embryonal carcinoma is a malignant germ cell tumor (GCT) composed of primitive epithelial tumor cells that recapitulate early stages of embryonic development and show specific immunohistochemical expression of CD30 [4]. Testicular GCTs make up 95\% of testicular cancers and are the commonest solid malignancies in young men [5]. It should be noted that about $5 \%$ of patients of GCTs may present with a metastatic localization on the digestive tract [6]. Extragonadal GCTs are rare and account for only 1-5\% of all GCTs [7]. They most commonly occur in the mediastinum or sacrococcygeal region; however, they can occur at various other locations. Here, we report a case of a rare primary duodenal tumor with features of an embryonal carcinoma curatively resected with pancreaticoduodenectomy.

\section{Case Presentation}

A 35-year-old man presented to our hospital with intractable nausea and vomiting complaints. His medical history and family history were unremarkable. Clinical examination showed that the patient had a body mass index of $20.3 \mathrm{~kg} / \mathrm{m}^{2}$. Examination of the abdomen revealed epigastric distention without any abdominal mass.

Biologically, the patient presented with hemoglobin at $7.5 \mathrm{~g} / \mathrm{dL}$ in relation to iron deficiency anemia (serum iron: $16 \mu \mathrm{g} / \mathrm{dL}$, mean corpuscular volume: $65.6 \mathrm{fL}$ ). For this reason, he underwent transfusion with 6 units of packed red blood cells after he was admitted to our department. There was no excessive inflammatory syndrome (leukocytes: $4,400 / \mu \mathrm{L}$ and Creactive protein: $2.35 \mathrm{mg} / \mathrm{dL}$ ). Electrolytes and hepatic function were within normal limits. Tumor markers were measured as follows: carcinoembryonic antigen, $0.9 \mathrm{ng} / \mathrm{mL}$; carbohydrate antigen, 19-9. $41.5 \mathrm{U} / \mathrm{mL}$; carbohydrate antigen, 125: $12.1 \mathrm{U} / \mathrm{mL}$.

A computed tomography (CT) scan of the chest, abdomen, and pelvis showed a circumferential lesion thickening of up to $3.5 \mathrm{~cm}$ at the level of the third portion of the duodenum (Fig. 1). Although up to $20 \mathrm{~mm}$, several lymphadenopathies were noted around the duodenum, no aortocaval, retroperitoneal lymphadenopathy, or secondary lesion was observed.

An esophagogastroduodenoscopy (EGD) was performed to further investigate his anemia and vomiting, which revealed a circumferential mass within the third portion of the duodenum (Fig. 2). Histopathology of biopsy materials from the duodenal mass showed it most

\section{Karger's'}




\section{Case Reports in Gastroenterology}

Case Rep Gastroenterol 2021;15:269-275 DOI: $10.1159 / 000512421$

c) 2021 The Author(s). Published by S. Karger AG, Basel www.karger.com/crg

Yamamoto et al.: Primary Duodenal Carcinoma with Embryonal Carcinoma Features in a Young Man

likely to be a poorly differentiated adenocarcinoma with positive immunoexpression for keratin (AE1/AE3) and negative for CD3, CD20, and p40.

After discussion at a multidisciplinary tumor board, he was diagnosed with severe bowel obstruction and anemia caused by primary duodenal cancer, and pancreaticoduodenectomy was performed. Intraoperatively, examination of the abdominal cavity did not reveal any peritoneal carcinomatosis or any other tumoral lesions. A subtotal stomach preserving pancreaticoduodenectomy with regional lymph node dissection was performed. His postoperative course was uneventful.

Macroscopically, there was a papillary elevated lesion measuring $65 \times 57 \mathrm{~mm}$ in size, centering caudal to the duodenal papilla, and growing along the duodenum. Microscopically, cells with large, pleomorphic vesicular nuclei displaying single or multiple macronucleoli, amphophilic cytoplasm, and prominent mitotic figures grew in a solid pattern. There was no ductal architecture or squamous differentiation. Immunohistologically CD30 and SALL4 were positive, CK7 was partially positive, and CDX-2, c-kit, and PALP were only partially positive in a small fraction. On the other hand, CK20, S100, melanA, AFP, synaptophysin, chromogranin A, and HCG $\beta$ were negative. The Ki-67 labeling index was over $50 \%$. The tumor was diagnosed as a carcinoma with embryonal carcinoma features. There was mild lymphovascular invasion. The tumor cells spread mainly on the duodenal mucosal surface and partially invaded the subserosal layer. There was no evidence of infiltration into the pancreas. The UICC TNM staging was T3N2M0, stage IIIA (Fig. 3).

There was a small area of nuclear stratification in the duodenal mucosa around the tumor, the tumor spread mainly on the mucosal surfaces, and no other primary lesion could be identified on CT imaging, suggesting a duodenal origin. Testicular ultrasound revealed only slight calcification in his testis. Histologic confirmation was not made because the patient refused orchiectomy or any other procedure. The patient is being closely followed without adjuvant therapy because of his refusal. Currently, at 12 months of follow-up, there is no evidence of active disease, with the levels of AFP and HCG-beta being within normal limits.

\section{Discussion}

This is a case of primary duodenal cancer with unusual characteristics of embryonal carcinoma. Embryonal carcinoma of the duodenum is rare and is not often reported as a primary tumor [8]. In most cases of metastatic duodenal germ cell tumors (GCTs), the images appear to be clustered with swollen lymph nodes of the retroperitoneum. Local extension from the retroperitoneal lymph node into the GI tract is a common method of spread [9].

In the case of metastatic GCTs, ultrasonography and histological examination with orchiectomy are performed to search for the primary lesion. When searching for primary lesions, "burned-out" tumors must also be considered [10-12]. In our case, the primary lesion was searched and a calcified lesion suspected to be a "burned-out tumor" was found. However, due to the patient's refusal, no systematic diagnosis with orchiectomy has been performed, and the possibility of metastatic disease cannot be ruled out. However, there are few cases where the duodenal lumen side is the main site of the lesion, and without clustered masses of swollen lymph nodes of the retroperitoneum, as in our case. This is one of the reasons to support this case as a primary lesion.

If GCT is diagnosed preoperatively, even if no obvious primary can be pointed out, chemotherapy will be preceded according to the guidelines [13]. Chemotherapy was markedly

\section{Karger'=}


Case Reports in
Gastroenterology

Case Rep Gastroenterol 2021;15:269-275

DOI: $10.1159 / 000512421$

(c) 2021 The Author(s). Published by S. Karger AG, Basel www.karger.com/crg

Yamamoto et al:: Primary Duodenal Carcinoma with Embryonal Carcinoma Features in a Young Man

effective for metastatic duodenal GCTs, and there are several reports of progress without surgery [14-16]. It is not clear whether chemotherapy is successful for primary duodenal cancers with the characteristics of an embryonal carcinoma, as in our case. Therefore, it is considered appropriate to select surgical treatment for resectable lesions.

Similarly, with regard to postoperative adjuvant therapy, it has been reported that recurrence of nonseminomatous testicular germ cell tumors of stage IA and IB is significantly reduced by performing adjuvant chemotherapy [17]. However, in this case, there is no clear evidence of the effectiveness of adjuvant therapy when gross curative resection is performed. Therefore, in consideration of the possibility of a metastatic tumor in this case, it is necessary to continue to carry out careful follow-up by performing CT from the chest to the pelvis, ultrasonography of the testes, and regular measurement of tumor markers.

\section{Acknowledgments}

The authors would like to thank Editage (www.editage.com) for English language editing.

\section{Statement of Ethics}

We have reported this case in compliance with the Declaration of Helsinki. Informed written consent was obtained from the patient for publication of this case report and any accompanying images.

\section{Conflict of Interest Statement}

The authors have no conflicts of interest to declare.

\section{Funding Sources}

No funding was received for this research.

\section{Author Contributions}

N. Yamamoto contributed the design of the report. N. Yamamoto, K. Washimi, and T. Kishida drafted the manuscript. M. Murakawa, M. Kamiya, and Y. Kamioka collected the data. Y. Rino, M. Masuda, and S. Morinaga revised the manuscript. All authors read and approved the final version of the manuscript.

\section{Karger'=}




\section{Case Reports in Gastroenterology}

\section{References}

1 Qubaiah O, Devesa SS, Platz CE, Huycke MM, Dores GM. Small intestinal cancer: a population-based study of incidence and survival patterns in the United States, 1992 to 2006. Cancer Epidemiol Biomarkers Prev. 2010 Aug;19(8):1908-18.

2 Cloyd JM, George E, Visser BC. Duodenal adenocarcinoma: advances in diagnosis and surgical management. World J Gastrointest Surg. 2016 Mar;8(3):212-21.

3 Zhang S, Cui Y, Zhong B, Xiao W, Gong X, Chao K, et al. Clinicopathological characteristics and survival analysis of primary duodenal cancers: a 14-year experience in a tertiary centre in South China. Int J Colorectal Dis. 2011 Feb;26(2):219-26.

4 Matoso A. Embryonal carcinoma. PathologyOutlines.com website. 2019. https://www.pathologyoutlines.com/topic/testisembryonal.html.

5 Siegel RL, Miller KD, Jemal A. Cancer statistics, 2016. CA Cancer J Clin. 2016 Jan-Feb;66(1):7-30.

6 Chait MM, Kurtz RC, Hajdu SI. Gastrointestinal tract metastasis in patients with germ-cell tumor of the testis. Am J Dig Dis. 1978 Oct;23(10):925-8.

7 McKenney JK, Heerema-McKenney A, Rouse RV. Extragonadal germ cell tumors: a review with emphasis on pathologic features, clinical prognostic variables, and differential diagnostic considerations. Adv Anat Pathol. 2007 Mar;14(2):69-92.

8 Barbieux J, Memeo R, De Blasi V, Suciu S, Faucher V, Averous G, et al. Real case of primitive embryonal duodenal carcinoma in a young man. World J Gastroenterol. 2017 Jan;23(4):730-4.

9 Johnson DE, Appelt G, Samuels ML, Luna M. Metastases from testicular carcinoma. Study of 78 autopsied cases. Urology. 1976 Sep;8(3):234-9.

10 Comiter CV, Renshaw AA, Benson CB, Loughlin KR. Burned-out primary testicular cancer: sonographic and pathological characteristics. J Urol. 1996 Jul;156(1):85-8.

11 Angulo JC, González J, Rodríguez N, Hernández E, Núñez C, Rodríguez-Barbero JM, et al. Clinicopathological study of regressed testicular tumors (apparent extragonadal germ cell neoplasms). J Urol. 2009 Nov;182(5):2303-10.

12 George S, Al-Taleb A, Hussein S. Retrogressed (burned-out) testicular germ cell tumor disguising as duodenal gastrointestinal stromal tumor. OHG Reports. 2015;4(2):114-15.

13 Albers P, Albrecht W, Algaba F, Bokemeyer C, Cohn-Cedermark G, Fizazi K, et al.; European Association of Urology. Guidelines on testicular cancer: 2015 update. Eur Urol. 2015 Dec;68(6):1054-68.

14 Morinaga M, Osada T, Kon K, Kato J, Konishi M, Shibuya T, et al. Metastatic seminoma in the duodenum: diagnosis with endoscopy followed by successful treatment. Intern Med. 2014;53(24):2777-81.

$15 \mathrm{Al}$ Ani AH, Al Ani HA. Testicular seminoma metastasis to duodenum. Misdiagnosed as primary duodenal tumor. Int J Surg Case Rep. 2016;25:149-52.

16 Emre Duygulu M, Kaymazli M, Goren I, Yildirim B, Sullu Y, Nural MS, et al. Embryonal Testicular Cancer with Duodenal Metastasis: Could Nausea and Vomiting be Alarm Symptoms? Euroasian J Hepatogastroenterol. 2016 Jul-Dec;6(2):198-201.

17 Gumus M, Bilici A, Odabas H, Ustaalioglu BBO, Kandemir N, Demirci U, et al. Outcomes of surveillance versus adjuvant chemotherapy for patients with stage IA and IB nonseminomatous testicular germ cell tumors. World J Urol. 2017;35(7):1103-10. https://doi.org/10.1007/s00345-016-1964-6. 
Case Reports in Gastroenterology
Case Rep Gastroenterol 2021;15:269-275

DOI: 10.1159/000512421

(c) 2021 The Author(s). Published by S. Karger AG, Basel www.karger.com/crg

Yamamoto et al.: Primary Duodenal Carcinoma with Embryonal Carcinoma Features in a Young Man

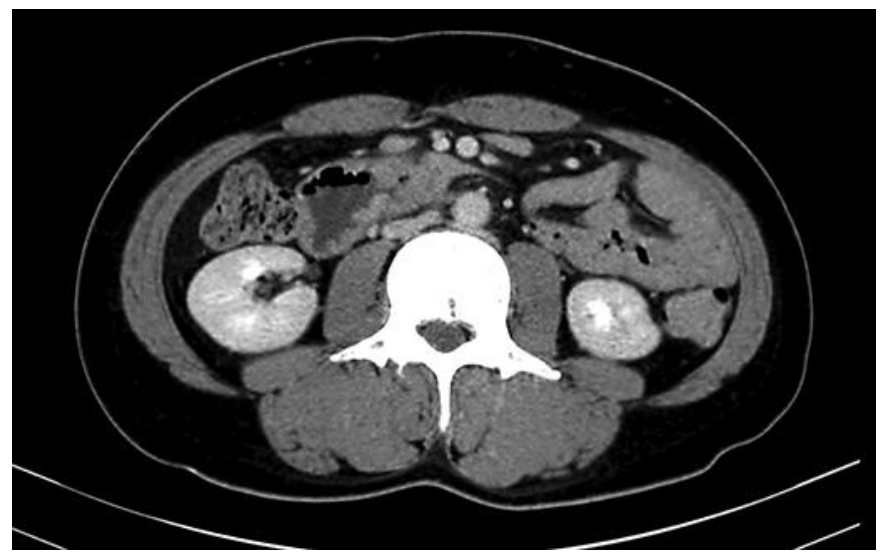

Fig. 1. Abdominal CT showed a circumferential lesion thickening of up to $3.5 \mathrm{~cm}$ at the level of the third portion of the duodenum. No aortocaval nor retroperitoneal lymphadenopathy was observed.

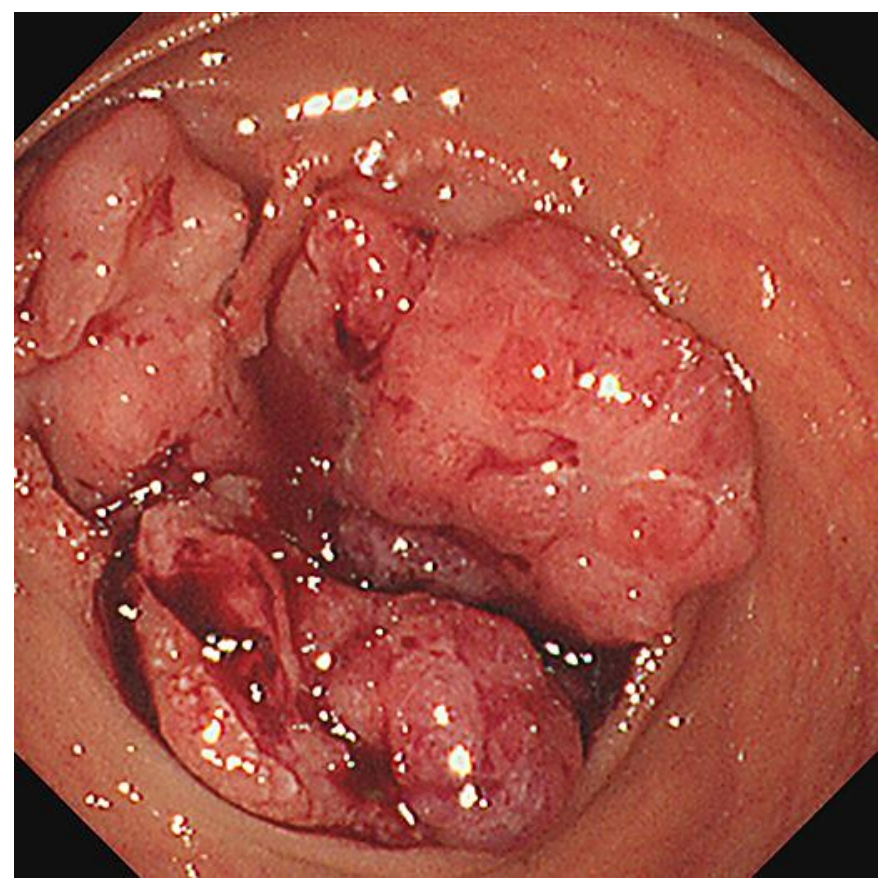

Fig. 2. EGD showed a circumferential mass within the third portion of the duodenum. 


\section{Case Reports in Gastroenterology}
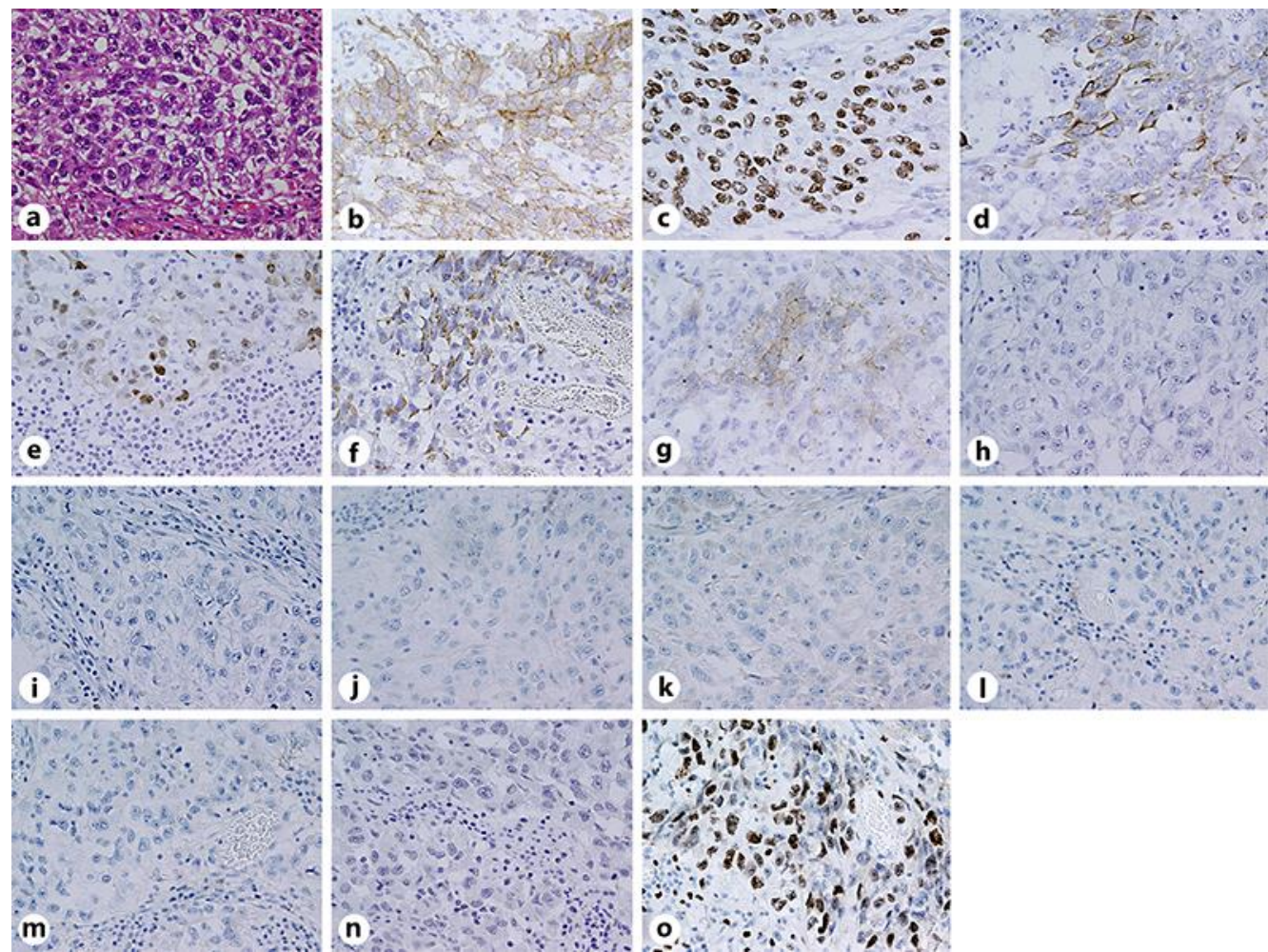

Fig. 3. Histological findings of the operative specimen showing the features of an embryonal carcinoma: the cells with large, pleomorphic vesicular nuclei displaying single or multiple macronucleoli, amphophilic cytoplasm, prominent mitotic figures grow solid pattern (a). Immunohistologically CD30 (b) and SALL4 (c) were positive, CK7 (d) was partially positive, and CDX-2 (e), c-kit (f), and PALP (g) were only partially positive in a small fraction. On the other hand, CK20 (h), S100 (i), melanA (j), AFP (k), synaptophysin (I), chromogranin A (m), and HCG $\beta$ (n) were negative. The Ki-67 labeling index was over 50\% (o). Original magnification $\times 400$. 